\title{
A structural equation model of principals' communication patterns, funds management and school-community relationship
}

\author{
Valentine Joseph Owan, John Ekpenyong Asuquo and Michael E. Asuquo \\ Department of Educational Management, University of Calabar, Nigeria \\ Correspondences should be addressed to Valentine Joseph Owan iD owanvalentine@gmail.com \\ Received 24 September 2020; Revised I November 2020; Accepted 4 November 2020
}

Recent studies tend to explain the importance of communication in the organisation as well as prescribing the most commonly practised techniques adopted by school managers. Studies on financial management are quite limited with the available ones suggesting that poor financial management is a source of conflict between school leaders and host communities. Little seems to be known on the connection between principals' communication patterns and funds' management as predictors of school-community relationship. This study builds on existing studies and appears to be the first to assess the linkages between principals' communication patterns, fund management practices and schoolcommunity relationship based on empirical rather than subjective data. A structural modelling approach was adopted to examine the nexus using quantitative primary data obtained from a random sample of 2108 respondents. A questionnaire which was designed and validated by the researchers served as the data collection device. Collected data were subjected to Exploratory and Confirmatory Factor Analyses, as well as Multiple Regression Analysis. Findings revealed various significant communication, funds management and school-community relationship practices that are available for adoption. However, it was found that the extent to which principals utilised such practices were below expected minimum standards. It was also found that there were no significant partial and composite effects of principals' communication and funds management practices on school-community relationship (SCR). Based on these results, relevant theoretical, policy and practical implications are discussed.

Keywords: Communication, community, factor analysis, funds management, principals, relationship, school

\section{Introduction}

One of the goals of secondary education in Nigeria is to provide an increasing number of primary school leavers with the opportunity for higher quality education, irrespective of sex, or social, religious, ethnic background and culture (FRN, 2004). It has a diverse curriculum to cater for the differences in talent, opportunities and roles performed by students after their elementary education course. Secondary schools are designed to equip students to live effectively in the modern age of science and technology and to contribute to the development of the culture, arts and languages of Nigeria. Again, secondary education focuses on raising a generation of people who can think for themselves, respect the views and feeling of others, respect the dignity of labour, and appreciate those values specified under the broad national aim, and life of citizens (FRN, 2008).

To achieve the goals of secondary education, there is a need for the community in which the school resides to work in cooperation and congruity with the school not just in the upbringing and welfare of the students but to also offer help in the preparation and upkeep of the school infrastructure just as the effective management and administration of the school. The community, therefore, has a role to play in shaping the policies and finances of the school, just as the school, in turn, must function to meet the social needs, yearnings and aspirations of the community by turning out a literate population and transmitting the cultural values of the community to the youth. Improving the school-community nexus is key because the two bodies depend on each other and failure of either body to assume its role can prompt the breakdown of the instructional framework with its subsequent impact on the general public (Owan, 2019).

For schools to be successful in the training of the children, there is a need to know considerably, the families from where learners come from (Bakwai, 2013). It is difficult to gain an understanding of students' families without any form of relationship between teachers and parents. Under an ideal situation, both the community 
and school are supposed to operate closely and cooperate for predetermined goals to be achieved (Madukwe et al., 2019). Such cooperation would require that stakeholders such as principals, teachers, parents and community leaders see themselves as partners in the educational development of the child (Owan, 2019).

However, despite the benefits that comes with the union, there seems to be several problems bordering around school-community relationship globally (Brady, 2013; Dumitriua, 2013; Eubanks, 2017). A growing body of research in Africa reveal several issues among schools and host communities leading to of unfriendly ties (Atambila, 2012; Kalemba, 2013; Russell, 2009; Waek, 2017). In Nigeria, different studies have also demonstrated similar trends of poor school-community relationship (Anthony et al., 2017; Ataine \& Nkedishu, 2017; Bakwai, 2013; Ezimoha \& Ngerem, 2016). These poor relationships often lead to weak school administration, which inevitably produces a situation that schools struggle to contribute to the improvement and advancement of individuals in society (Mbokazi, 20I2). It is worth mentioning that most secondary schools in rural communities of Cross River State do not seem to be in tandem with their host communities.

Many times, principals and teachers have been bullied and assaulted by students, parents and relatives whenever there is a need to enforce school policies (Obeten, 2019). In an instance cited in Owan (2019), a parent mobilised her relatives and invaded a school beating up a teacher mercilessly for disciplining her child. The researchers have also experienced an instance where an instructor sexually harass a married lady in the community he was posted to teach, leading to her husband and some members of the community invading the school to beat the teacher and damage school properties. Consequently, most community members become unenthusiastic and lackadaisical about attending school events such as PTA meetings, inter-house sports ceremonies, cultural days, award ceremonies and so on, due to the alienation that has distanced most schools from members of their host communities.

In a revelation, Palmieri and Palma (20I7) explained that the home-school relationship has changed, because parents are no longer seeing themselves as teachers' devoted partners, yet are more disposed to be defensive of their kids. Such attitudes often restrict the potential for the school to function and the opportunity to establish an educational programme (Palmieri \& Palma, 2017), as well as obstructing the autonomy of schools (Ungar, 2009). The effect of this poor attitudes on the performance of the school, students and the society is catastrophic (Odigwe et al., 2018; Owan \& Agunwa, 2019). In most cases, neither the school nor the community seems to be taking responsibility for the poor relationship, making it more difficult for resolutions to be reached. Instead, what is rather common, in most cases, is a separation where schools are on their own and are not interested in involving the communities in their activities and vice versa (Owan, 2019).

Given the need for participative management, shared leadership and decision making (Omorobi et al., 2020), it is quite disheartening that there is near zero collaboration between the school and her host community. Although many parents complain about misappropriation of funds by principals and unprofessional behaviours of some teachers ranging from excessive bullying of students, corporal punishments frequently administered on their children, use of students for domestic chores to even sexual harassment, among others. A cohesive school-community relationship would have provided a better platform for addressing these issues between the school and the community. The government, at all levels in Nigeria, have tried to improve the state of school community relationship through various efforts.

For instance, school community relationship has been included in the teacher education curriculum to equip trainee-teachers with the desired behaviours they must demonstrate after gaining employment, to relate well with host community members at their places of primary assignment. The government had also reduced the amount of PTA levies and other school charges usually imposed on students in public secondary schools and have adopted the child rights act to protect the children's rights at all times. Sensitisation campaigns have also been organized by youth corps members in some areas to enlighten teachers and rural community members on the need to maintain a healthy relationship. Furthermore, several retraining programs have also been organized to sensitise teachers on the expected attitudes they should portray and those they should avoid to maintain a cohesive relationship with members of host communities. 
Many scholars (e.g. Anthony et al., 2017; Ataine \& Nkedishu, 2017; Ezimoha \& Ngerem, 2016; Owan, 2019; Owan et al., 2018) have carried out empirical surveys that have made sound recommendations for improving school-community relationship. Yet the issue of poor school-community relationship is still common within the formal school system. It was based on the persistence of this issue that raised the curiosity of the researchers to investigate whether principals' communication patterns and funds management have any connection with school-community relationship. The researchers considered these variables because the characteristics possessed by different principals may affect their relationship with students, teachers and/or the larger community.

\section{I.I. Principals' Communication Pattern}

Communication is a term derived from the Latin word "communicare" which means "to share", "to impart", "to transmit" and "to make common". It connects individuals, groups and in certainty penetrates each part of the organisational life (Peretomode, 20I2). Communication is the life-wire of any organization and the basic administrative tool the principal uses in ensuring that educational goals are achieved (Arop et al., 20l8b). Communication is a genuine apparatus required in an organisation to tackle issues and achieve objectives, but can never occur in confinement, there must be a sender, a collector, the message and the medium used to transmit (Anya \& Ekezie, 2019). Communication in organizations is essential since it is a scaffold through which messages, data and thoughts are transferred from one individual, spot or thing to another (Arop et al., 20l8b). Through communication, fundamental administration functions such as planning, organizing, staffing, directing, coordinating, reporting and budgeting are facilitated.

When principals' communication style is unfavourable to teachers working with them, there is that tendency that such teachers would not co-operate with the principal and performance would be affected. For better communication in a school, the principal must first conceive ideas and relate such ideas to his staff and other stakeholders. However, principals adopt certain styles when they communicate and these styles to a great extent could determine the effectiveness of a school system and the nature of the school-community relationship (Akinwale \& Okotoni, 2018). Studies have attempted to associate the communication process to other depended variables.

For instance, the study of Ezenwekwe (2013) researched "teacher-principal communication patterns as correlates of effective school administration in public secondary schools in Onitsha Education zone of Anambra State, Nigeria". The study identified communication patterns that were commonly used by public secondary school principals in the state. The result concluded that schools, where result-driven communication was used, are better managed and that the styles contributed to increasing in the quality of school administration. This study has a relationship to the present study because it shows the importance and inevitability of communication between school leaders and teachers in running the school. Communication between teachers and principals is not the same as between principals and the community. However, since many teachers are employed from the community (Owan, 2019), it can be argued that such a principal-teacher communication flow has a way of reaching the wider community because teachers may communicate crucial decisions made from such communication (principal-teacher) to students to take home to their parents.

Another study was conducted by Guo, et al. (2015) on the "effects of leaders' verbal communication style, on employee's job satisfaction." The consequences of the examination indicated that despotic verbal communication can be utilized by superiors in various associations. The examination inferred that the dictatorial verbal communication style prompted low employment fulfilment while supportive verbal communication style resulted in improved occupation execution. This finding has an indirect link to the present study by the implication that an autocratic leader may struggle to relate with community leaders to foster cooperation. On the other hand, leaders with a supportive pattern of communication can build a cohesive workforce with community leaders. The study of Guo et al did not cover school community relationship as the main variable but focused on employee satisfaction. This means that the indirect association derived is subjective and not backed by available evidence, making it imminent for a study to associate principals' communication to school-community relationships. 
The investigation of Akinwale and Okotoni (2018) assessed administrators' correspondence styles and regulatory effect on secondary schools in Osun State, Nigeria. The outcomes demonstrated that the normal communication styles embraced by chiefs in Osun state were comprehensive, open and emphatic in a specific order. The outcomes further demonstrated that only a couple of secondary school directors embraced the forceful correspondence style in their different schools. The investigators reasoned that administrators' communication styles assume a significant function in the smooth running of schools just as upgrading adequacy. As a critique against the study of Akinwale and Okotoni (2018) vis-à-vis the present study, is its disconnection from the school-community relationship. The study only uncovered findings showing the pattern, flow and nature of communication adopted by school principals and further tying it to the smooth running of the schools.

Discoveries uncovered from the study of Anya and Ekezie (2019) revealed among others, that free progression of information improved successful administration; the grapevine helped in the quick scattering of information; communication channels encouraged connections among peers in secondary schools. It was presumed that communication, be it formal or casual assumed an exceptionally pivotal function in the compelling administration of secondary training and in utilizing the suitable channels to get the school exercises underway and to make the two (educators and directors) to partake successfully in the administration of the school. This study, like other earlier works, explained the importance of communication using empirical evidence but failed to create a causal link between such important role supposedly played by communication in building effective school network to the larger community.

Using a sample of 27I principals, 396 vice principals and 813 teachers selected through the census and simple random sampling techniques, the study of Owan (2019) found that there was a significant correlation between school-community communication and secondary school system effectiveness; school-community collaboration was also revealed to be significantly related to the effectiveness of the school system. While the study Owan (2019) appears to be the first to focus on school-community communication, the outcome of such a link was studied only from the perspective of the school effectiveness, suggesting that efforts should be channelled towards understanding the role of school-communication on the effectiveness of the school. The present study was designed to cover this gap. The results of another study showed that effective communication has a noteworthy association with human relationship, work execution and organisational goal fulfilment (Arop et al., 20l8b). In light of these discoveries, it was inferred that powerful communication prompted great human relationship, advanced work execution and enhanced the achievement of stated goals. The present study is implicit on the conclusion of Arop et al. (2018) because effective communication can be used to promote effective cooperation (human relations) between the school and external stakeholders such as the larger community.

Furthermore, the study of Madukwe et al. (2019) identified principals' effective communication as an administrative networking strategy that can be used to promote supervisory effectiveness of school leaders. This implies that communication can also be used to create external networks for improving service delivery in the school. Studies have also found that effective communication practices adopted by secondary school principals are very significant in the management of conflict and improvement of teachers' quality of service (Arop et al., 2018a; Owan, 2018; Owan \& Agunwa, 2019). Suggesting that school-community conflicts can be effectively managed through dialogue between the school and community leaders. The contextual analysis of Bavuso (2016) investigated various strategies for conveying among schools, guardians, and community individuals with an end goal of finding the best type of communication. Discoveries demonstrated that secondary school partners favoured present day innovation to communicate by and large, yet that in specific circumstances, more conventional strategies were more well known. Overseers, educators, and guardians would profit by analysing the usefulness and attainability of expanding the utilization of web-based media for parent and community outreach, yet additionally from considering the utilization of customary techniques when reasonable.

Another study used two rounds of semi-structured interviews to explore School-Family-Community Engagement in Community Dialogue (Cook et al., 2017). Critical race theory in training guided the community 
dialogues implementation and subjective investigations. Discoveries illuminated participant appreciation for sharing narratives, creating awareness of social contrasts, and raising basic attention to prepare community change. Ramifications of the school community dialogues on instructive results and advising practice are additionally depicted. The investigation of Duslak and Geier (2016) inspected the impacts of meeting recurrence, organized meetings times, yearly arrangements, and demographic factors on school counsellors' view of their relationship with their school heads. Aftereffects of a regression analysis demonstrated that meeting recurrence represented $26.7 \%$ of the difference in school counsellors reported relationship quality scores. More successive meetings were related to higher evaluations of relationship quality. The presence of organized meeting time and a yearly agreement decidedly affected relationship quality less significantly. This demonstrates that meeting between a school head and instructor should not always be officially organized to be a powerful strategy for building connections between these two parties. School advocates and directors can base practice from these discoveries by purposefully making open doors for continuous meetings.

The study of Boudreaux (2017) used a quantitative methodology to analyse school leaders' role in community support and involvement. Results emerged that guardians/parents were compelling forces in making decisions for schools; schools maintained a clear, two-route communication with guardians/parents and the community; schools worked superbly in empowering parents/guardian inclusion; educators gave parents/guardians helpful information about students' learning; parents/guardians comprehended what was happening in schools; parents/guardians upheld educators, adding to the academic performance of students; community individuals supported educators, adding to their prosperity with learners; the community people being served provided strong support to schools. The study of Boudreaux (2017) had rich findings which are useful to the present study. However, the study has a weakness - a small scope and a small sample size, which limits its dependability and generality. Thus, a broader study or a study from another cultural context is required. Having reviewed extant literature on the communication variable, it makes sense to consider the next variable - principals' funds management.

\section{I.2. Principals' Funds' Management}

Funds management is one of the major tasks of the principals. It entails the sourcing and effective use of funds. The central purpose of financial management is the raising of funds and ensuring that the funds are utilized most effectively. Principals are expected to keep accurate records of all income to the school as well as keep a proper account for the disbursement and expenditure of such monies. School administrators, in addition to other duties, are expected to ensure that they prepare realistic budgets, explore sources of revenue generation to provide some essential needs of the school, keep proper accounts for disbursement of school funds, priorities financial allocation according to the needs of the school. Since schools are mostly financed from citizens' taxes (Swartz, 2009), this makes them freely accountable when utilizing these public assets.

Schools' accounting officials should maintain control of public resources (funds) through activities such as keeping up a system of budgetary controls, internal audits, including appropriate procurement techniques, maintaining accountability and controlling income (Myende et al., 2018). The principal is also relied upon to represent, control expenses and assume liability for the management and security of school resources (Boma, 2018; Idris, 2018; Nwafukwa \& Sunday, 2015; Okeze et al., 2018). The above obligations suggest that the school leader is essentially answerable for the administration of school funds, including the observation, checking and control of the school budget. Therefore, poor management of funds and unaccountability by principals could diminish the value host communities place on the accounting system of the school, especially when the funds in question, has something to do with the communities' contribution (e.g. PTA levies, community donations, etc).

Most often, many stakeholders are interested in assessing principals' spending of school internally generated funds such as funds from channels such as PTA levies, donations, pledges, and many others of which they are aware (Hooge et al., 2012; Ukpong \& Uzoigwe, 2019). Past investigations mirrored principals' absence of eagerness to share their capacity, particularly with the school governing board. For instance, studies have documented that a couple of individuals from the school governing board meet up to steal school reserves due to principals' non-inclusive approach to financial and material resource management, creating a harmful culture 
of shared corruption (Heystek, 2004; Mestry, 2006, 20I0; Xaba, 20II). These contaminated connections between the head, school governing board, educators and parents on school financial issues could produce a challenged bellicosity inside the school setting and its community. However, the study of Myende et al. (2018), saw an alternate picture, where the contribution of partners made it simple for chiefs to execute respected and responsible school financial administration.

The study of Udoh-Uwah et al. (2018) assessed the competence of secondary school principals in managing financial resources as a predictor of institutional goal attainment using a stratified sample of 120 respondents. With Pearson Product Moment Correlation Analysis, all the hypotheses formulated were tested at the .05 alpha level. Findings revealed that principals' financial management competence accounted for $37.21 \%$ of the total variance in the attainment of secondary schools' goals. This indicated a moderate positive relationship between the exogenous and endogenous variables. Even though the dependent variable of the study of UdohUwah et al. (2018) - goal attainment did not fully reflect school-community relationship, it has some indirect association, as schools that attain goals are always likely or presupposed to be relating well with their host communities (Bassey et al., 2019; Mbon et al., 2020; Owan, 2019; Owan et al., 2019).

In a South-African study, Myende et al. (2018) explored the successful financial management practices of five novice principals based on qualitative data. Contextual data were collected through interview and other secondary documents. Findings uncovered a new pattern of accountability relationship which countered the progressive relations among schools and the community, or between the division and the provincial setting. The investigation perceived vertical, flat and descending accountabilities, which were supported without anyone else's driven inspiration, moral uprightness and social formative duties. It was concluded that instead of being an obsessive issue, school financial management offered strategy and practice potential to create comindful administration.

In another study, Ogundele et al. (20/2) assessed school-community relationship as a predictor of variables such as principals' administrative effectiveness, school plant provisions, school personnel services and instructional activities in secondary schools. Using a correlational research design, with a sample of 2000 randomly selected participant (such as Principals, Vice Principals, PTA leaders, school prefects and representative of religious bodies), it was found that the school community relationship significantly predicted all the dependent variables to a high extent. This implies that a healthy school-community relationship would promote administrative effectiveness, leads to the procurement of school plant and other resources and boost the quality of instructional delivery by teachers. However, the researchers did not explain the estimated relationship revealed by their study.

\section{I.3. The Present Study}

The review of literature indicates that many studies abound on principals' communication and financial management. Most studies tend to explain the importance of communication in the organisation as well as prescribing the techniques most commonly adopted by school managers. The present study extended the work of Owan (2019) which revealed that school-community communication is significantly associated to the effectiveness of the school, with implications that an effective school is one that relates well with its host community (Bassey et al. (2019). While the approach is clever, it could be misleading in some situations where communications between the school and community do not lead to a healthy relationship, because communication is also used during conflicting situations to express dissatisfaction (Arop et al., 2018a; Owan, 2018). Therefore, a piece of empirical evidence (especially one based on a large-scale assessment) is needed to clarify the underlying relationship between principals' communication patterns and school-communication relationship.

Studies on financial management are quite limited with the available ones suggesting that poor financial management is a source of conflict between school leaders and host communities (Myende et al., 2018). The conclusions reached in these studies are subjective and not based on empirical data. The present study builds on existing studies and seems to also be the first to assess the linkages between principals' communication patterns, fund management practices and school-community relationship based on empirical data. Thus, the 
present study also extended the works of Myende et al. (2018) to test for the nexus between the independent and dependent variables and provide an explanation regarding the extent to which the predictor variables contribute to the response variable. The present study is, therefore, very important because it would assist policymakers and relevant stakeholders to strengthen school-community ties for beneficial purposes such as rural development, school manpower and infrastructural supplies, effective service delivery and goal attainment at both ends.

This study would encourage the Ministry of Education to organize more refresher courses on schoolcommunity relationship for principals of secondary schools to enable them build a healthy school-community network with key stakeholders at the school, community to national levels. The present study would also help community members and society in general, to realize the need for school-community collaboration and enable them to identify their roles as partners in promoting institutional success for sustainable development. This may help bridge the gap between the school and the community by making them inter-dependent. This means that the research would help create awareness among administrators, education stakeholders, business organizations and community members to realize that the education of children is a joint effort by all.

\section{I.4. Theoretical Framework}

This study was based on the Human Relations Theory (HRT) by Elton Mayo (1933). The HRT was created based on the Hawthorne studies conducted by Professor Elton Mayo (1933) in the USA; and other leading advocates such as F.J Roethlisberger, W. E Moore and G. Friedmann in France. Human relations theory was developed as a reaction to Taylorism. Dismissing the natural and unthinking methodologies of F.W Taylor's Scientific Management, the theory proposed the execution of techniques for managing labourers as sociomental creatures. The HRT suggested that human mental and moral characteristics, for example, objectives, inspiration and values need to be considered. The theory assumes that personal development and growth, as well as employee goal setting, are essential to effective businesses. The movement also predicted that affirmative motivation derived from team goals and greater production resulted from encouragement and positive re-enforcement from employers. The theory also assumes that people desire to be part of a supportive team that facilitates development and growth. In this manner, if employees get exceptional consideration and are urged to partake, they see their work as essential, and they are propelled to be more productive, bringing about top-notch work. Other underlying assumptions of the HRT are as follows:

i. man is self-motivated (self-controlled and motivated by social needs);

ii. man requires to fulfil his capacity to develop skills maturely and productively;

iii. man is threatened and pressured by externally imposed incentives;

iv. the need for recognition and sense of belonging is very important;

v. Peer group pressure has more influence than management control;

vi. man seeks to satisfy personal needs and objectives within the organization.

The implication of the theory to this study is that the school and the community share a similar vision in the training of the child. The schools' goals include the training of the child for the future and the development of the society (community). The parents or community members, also send their children to school believing that the training students receive from school will enable them (students) improve their lives, the lives of their families, their communities and the society in general. There is, therefore, a union between the school and the community through the students who are the outputs from the school to the community. This union means that the community cannot function effectively without the school and vice versa. According to human relations theory, man is motivated by social needs, and that pressure has more influence than management control. These few assumptions highlight the need for the school and the community to relate well with each other for improved productivity and goal attainment.

\section{I.5. Research Questions and Hypotheses}

This study aimed to seek responses for the following research questions:

I. What is the extent of principals' communication patterns in secondary schools?

2. To what extent are funds managed by school principals in secondary schools? 
The study also tests the following hypotheses:

$\mathrm{H}_{1}$ : There is a significant partial and composite effects of principals' communication patterns and funds management on the school-community relationship.

$\mathrm{H}_{0}$ : There is no significant partial and composite effects of principals' communication patterns and funds management on the school-community relationship.

\section{Method}

\section{I. Research Design}

This study was based on the quantitative research method with a specific focus on the correlational research design. The correlational design is suitable for studies aimed at identifying and understanding the pattern of relationships underlying two or more variables of interest. Therefore, based on the adopted research design, the specific objectives of this study were to investigate the relationship between principals' communication patterns and school-community relationship; as well as the relationship between principals' funds management and school-community relationship.

\subsection{Participants}

The population of this study comprised 5545 participants (composed of 27I principals, 396 vice principals, 4336 teachers, 542 PTA leaders) distributed across 27I public secondary schools in Cross River State, Nigeria. Since the study is aimed at assessing principals' communication patterns and funds management as correlates of school community-relationship, school leaders and teachers represented schools while the PTA chairmen and their secretaries (who are usually parents from host communities) stood as proxies for their communities). The proportionate stratified random sampling technique was adopted in selecting 2217 respondents representing $39.98 \%$ of the population. In achieving this, $39.98 \%$ of the population in each stratum was computed. This sampling technique was adopted to guarantee fairness and representativeness, so that sample elements are selected in the same proportion as contained in the population and to ensure that the sample is large enough to allow for generalisations to be made to the larger population. Thus, the sample of this study is distributed as follows from the various stratum - principals $(n=108)$, vice-principals $(n=158)$, teachers $(n=1734)$ and PTA leaders $(n=217)$.

\subsection{Measures}

Three measures were of primary concern to the researchers - principals' communication patterns, funds management and school-community relationship. The first measure (principals' communication patterns) is operationally defined as the techniques employed by secondary school managers to prepare, encode/decode, transmit/receive ideas, policies, understanding, meanings, data or information to/from recipients/senders who are either within or outside the school environment, using appropriate media and making room to provide/receive feedback. The second measure (principals' funds' management) refers to the strategies adopted by principals to generate, procure and manage all internally- and externally-sourced financial-related assets for the effective management of human and material resources in the school. The third measure (School-community relationship) refers to the two-way symbiotic connection that exists between a school and its host community, with the rationale of eliciting cooperation from both ends.

The instrument used in eliciting data for the study was a questionnaire which was designed by the researchers and entitled: Principals' Communication, Funds Management and School-Community Relationship Questionnaire (PCFMSCRQ). The questionnaire was structured into two sections. Section A elicited responded demographic data while section $B$ comprised 18 four-points Likert scale items to assess the three measures earlier identified. The instrument was subjected to face and content validity by five experts (two psychometrists and three educational management experts). These experts ensured that items in the questionnaire were clear, unambiguous, and void of vague and double-barrelled statements. Items that were dysfunctional or that did not meet the characteristics of unambiguity, clarity, vagueness etc., were modified or eliminated with provisions made for improvement. Preliminary data obtained from the sample of respondents were used to subject the instrument to a construct validity through an Exploratory Factor Analysis (EFA). This was done to understand the factorial structure of the items and identify/eliminate items that are not in alignment with the various subscales. Confirmatory factor analysis was also performed to verify the results of the EFA and compare the models of this study to hypothesized criterion-based models for acceptability or otherwise. The internal consistency reliability analysis of the instrument was performed using Cronbach Alpha 
technique. The reliability coefficients of the instrument generally and the various sub-scales are presented in Table I.

\subsection{Data Collection/Analysis Procedures}

Before making physical contact with the selected schools as well as participants, the researchers sent letters to the school leaders informing them about the exercise and the targeted population. This was to enable timely preparation of themselves (school leaders), teachers and PTA representatives. Upon making physical contact with the targeted participants, a briefing session was held to explain the objective and importance of the exercise, as well as the need for them to provide dependable responses. Only those who were willing were allowed to participate in the study, were given the survey to complete. The exercise took three weeks and only correctly filled copies of the instrument were used for analysis. Preliminary data screening revealed that $2108(95.1 \%)$ copies of the instrument were correctly responded to and retained while $109(4.9 \%)$ copies with one error or the other were discarded. The data obtained from these 2108 respondents were used for all the analysis performed in this study. Descriptive statistics and structural equation modelling techniques were applied in analysing data, answering research questions and testing the null hypotheses. The analysis of this study was performed using SPSS version 25 software, while structural equation model was built using the Amos graphics software version 23 .

\section{Results}

\section{I. Exploratory Factor Analysis (EFA)}

Before performing the EFA, the researchers first checked if the data collected was from a sample large enough to be subjected to factor analysis. This was met using the Keiser-Meyer-Olkin (KMO) criteria of sampling adequacy. A KMO value of .86 was high enough to justify the use of factor analysis based on the sample. The Bartlett's test of sphericity was significant at 120 degrees of freedom with a Chi-square value of I3289.73. This indicates that there is no redundancy between the variables and that the observed correlation matrix diverges from the identity matrix, making it suitable for a data reduction technique (PAF) to be applied. The determinant of the correlation matrix $(.00 \mathrm{I})$ was greater than the criterion value $(0.0000 \mathrm{I})$, which shows that there is no multicollinearity among the variables. Having met all the assumptions for performing factor analysis based on the dataset, the EFA was performed using Principal Axis Factoring (PAF) as the extraction method, with a Promax rotation, to analyse the correlation matrix based on Eigenvalues greater than I. After 25 iterations, four factors were initially discovered which cumulatively accounted for $59.84 \%$ of the total variance (which is below the acceptable minimum of $60 \%$ ).

However, after examining the pattern and structure matrices, it was discovered that two variables denoted as PFMT_2 and PCP_5 did not load to any of the factors, thus, they were eliminated from the analysis. After eliminating the two variables, the analysis was re-performed and this time, three factors were revealed with Eigenvalues values greater than I, explaining a cumulative variance of $60.78 \%$ (which is greater than the acceptable minimum of $60 \%$ ). More specifically, Factor I with Eigenvalue of 3.52 explained $22.02 \%$ of the variance, factor 2 with an Eigenvalue of 3.45 explained 21.530 of the total variance, while factor 3 with an Eigenvalue of 2.756 explained $17.23 \%$ of the total variance. Apart from these three, other factors from factor 4 and below did not meet the Eigenvalue cut-off of above I (see the scree plot in Figure I). 


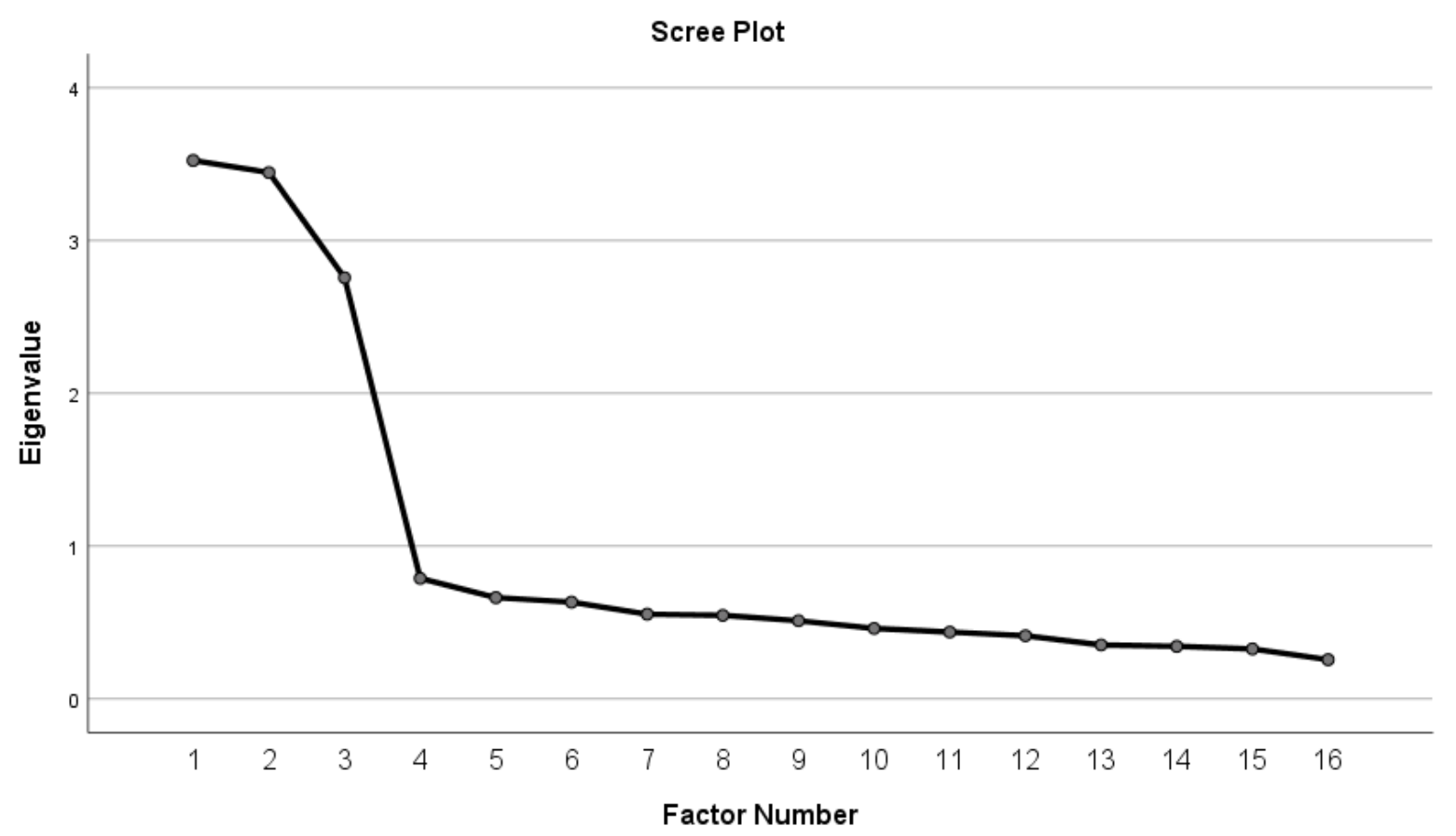

Figure I. Scree plot showing the number of factors and their Eigenvalues

After retaining three factors, the next step was to examine the loadings of each variable to the respective factors to see whether there are any loadings below the acceptable minimum of .40 . The examination revealed that all the variables loaded highly (above .40 ) to their respective factors. The leading items of each cluster were then examined for naming purposes. Consequently, the first factor was named 'Principals' Table I.

Pattern Matrix of the variables and their loadings to the respective factors

\begin{tabular}{|c|c|c|c|c|c|c|}
\hline Factors & Items & $\overline{\mathrm{X}}$ & SD & Factor loadings & Cronbach $\alpha$ & $\%$ of $S^{2}$ explained \\
\hline \multirow[t]{6}{*}{$\mathrm{T}$} & & & & & .89 & 22.02 \\
\hline & PCP_2 & 2.48 & 1.12 & .86 & & \\
\hline & PCP_4 & 2.49 & 1.12 & .86 & & \\
\hline & PCP_I & 2.52 & 1.12 & .80 & & \\
\hline & PCP_3 & 2.48 & I.II & .77 & & \\
\hline & PCP_6 & 2.49 & I.II & .66 & & \\
\hline \multirow[t]{7}{*}{2} & & & & & .85 & 21.53 \\
\hline & SCR_6 & 2.49 & 1.12 & .78 & & \\
\hline & SCR_3 & 2.50 & 1.12 & 77 & & \\
\hline & SCR_4 & 2.49 & 1.12 & .76 & & \\
\hline & SCR_5 & 2.52 & I.II & .72 & & \\
\hline & SCR_2 & 2.48 & I.II & .61 & & \\
\hline & SCR_I & 2.52 & 1.12 & .53 & & \\
\hline \multirow[t]{6}{*}{3} & & & & & .80 & 17.23 \\
\hline & PFMT_I & 2.52 & I.II & .74 & & \\
\hline & PFMT_4 & 2.46 & 1.12 & .70 & & \\
\hline & PFMT_6 & $2.5 \mathrm{I}$ & I.II & .68 & & \\
\hline & PFMT_3 & 2.51 & 1.12 & .63 & & \\
\hline & PFMT_5 & 2.48 & 1.12 & .57 & & \\
\hline Total & \multicolumn{3}{|c|}{$\begin{array}{l}\text { Kaiser-Meyer-Olkin (KMO) } \\
\text { Bartlett's Test of Sphericity }\end{array}$} & .86 & .73 & 60.78 \\
\hline
\end{tabular}

Extraction Method: Principal Axis Factoring.

Rotation Method: Promax with Kaiser Normalization.

a. Rotation converged in 4 iterations. 
communication pattern"; the second factor was named "School-community relationship"; the third factor was named "Principals' Fund management technique" (see Table I). The next step was to test for the reliability of the sub-scales and the overall instrument using Cronbach Alpha measure of internal consistency. Reliability coefficients such as $.89, .85, .80$ and .73 were obtained for the first factor (principals' communication patterns), second factor (school-community relationship), third factor (principals' funds' management) and the overall instrument respectively (see Table I).

\subsection{Confirmatory Factor Analysis (CFA)}

The CFA was performed to determine how well the variables measured their respective factors (constructs). It was used to evaluate the acceptability or otherwise of hypothesized models based on theoretical models. The CFA was also used to verify whether the relationships established by the EFA between observed variables (indicators) and their supposed constructs exist. The results in Figure 2 show the standardised measurement model of the CFA of the study. As depicted in Figure 2, the CFA factor loadings are the same or approximately the same as those derived from the EFA. However, in determining whether the model is acceptable or otherwise, several fit indices were used to evaluate the CFA model.

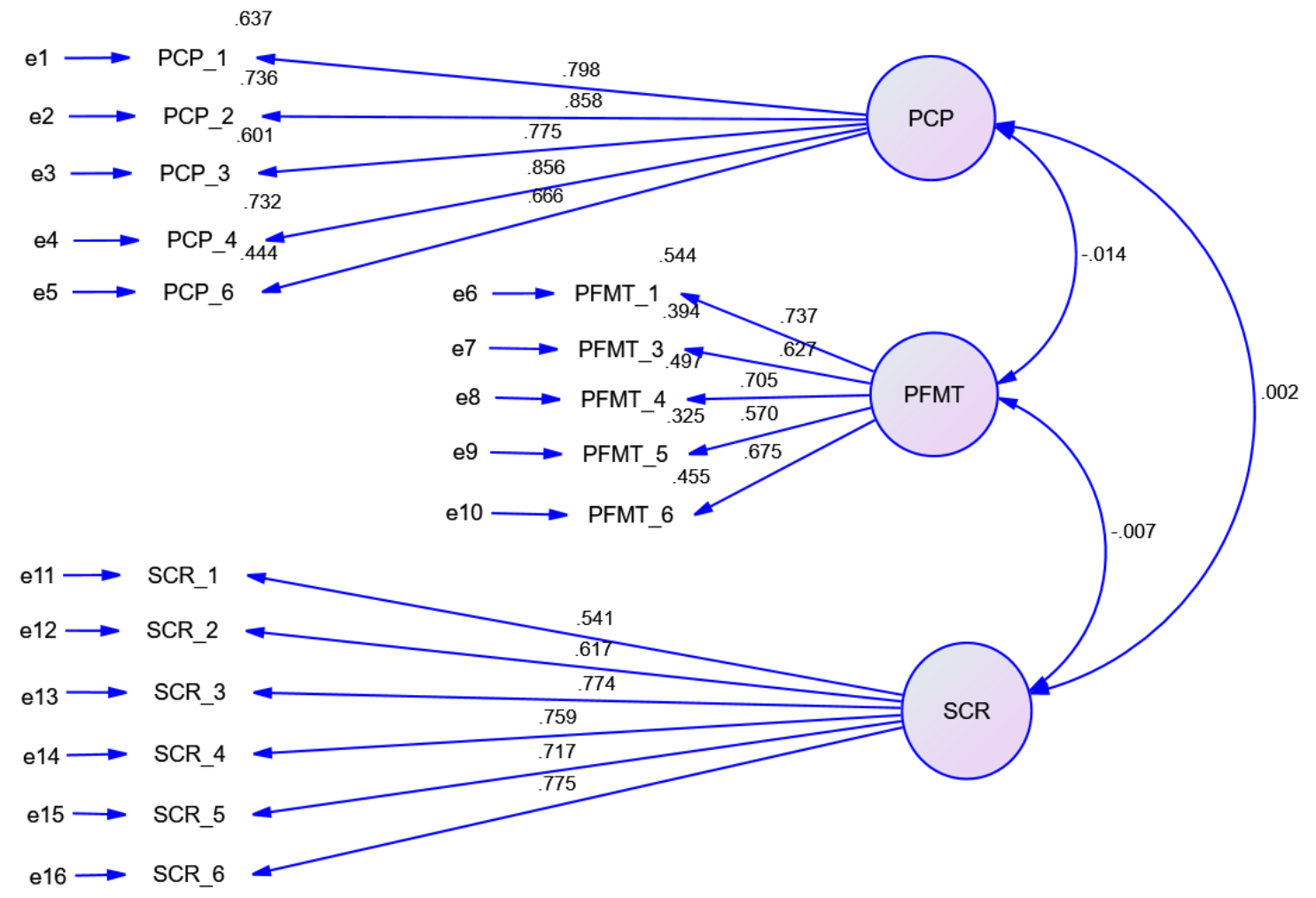

Figure 2. Measurement model of principals' communication patterns, funds management and school community relationship

The model of this study was evaluated using various fit indices due to the overlapping strengths and weaknesses of fit indices. The Chi-square index of 401.35 was significant at 101 degrees of freedom which ordinarily should mean that there is a discrepancy between the sample and fitted correlation matrix. However, due to the large sample size, it is not surprising that the model yielded such an index because the Chi-square is sensitive to sample sizes. The value of the Goodness of Fit Index (GFI) was .98, while the Adjusted Goodness of Fit Index (AGFI) was .97, indicating that the model accounted for a significant portion of the population covariance. The Normed Fit Index (NFI), Relative Fit Index (RFI), Incremental Fit Index (IFI) and the Tucker Lewis Index indicated values such as $.97, .97, .98, .97$ and .98 respectively. This attests to the fact that the model of this study improves the fit by $95 \%$ vis-à-vis the theoretical model. Another very important index that was used to evaluate the model of this study is the Root Mean Square Error of Approximation (RMSEA) which 
assesses how far a sample model is from a theoretical/population model. For this study, a value of .038 was obtained which indicates that the model of this study is quite excellent. Thus, with all these evidences, the model of this study was accepted for measurement purposes.

It is depicted in the model that maintaining close communication links with community leaders (PCP_I $[\beta=.80, t=43.57, \quad \mathrm{P}<.01])$, the use of native language of the host community (PCP_2 $[\beta=.86, t=47.67, P<.01])$, creating opportunities to meet with leaders of the host community (PCP_3 $[\beta=.78, t=41.73, P<.0 I])$, implementing suggestions made by community leaders towards school improvement (PCP_4 $[\beta=.86, t=48.31, P<.01])$ and adopting variety of communication styles in school administration (PCP_6 $[\beta=.67, t=33.73, p<.0 \mathrm{I}]$ ) are very significant patterns in principal's communication. Also, using funds to execute intended projects in the school (PFMT_I $[\beta=.74, t=35.18, p<.0 I]$ ), setting up an audit committee for the presentation of financial reports (PFMT_3 $[\beta=.63, t=24.97, p<.0 I]$ ), accounting for funds generated internally (PFMT_ $4[\beta=.7 \mathrm{I}, \mathrm{t}=24.48, \mathrm{p}<.0 \mathrm{I}]$ ), working harmoniously with other critical stakeholders in the generation, management and expenditure of school financial resources (PFMT_5 $[\beta=.57, \mathrm{t}=22.87, \mathrm{p}<.0 \mathrm{I}]$ ) and diverting school funds into more pressing areas than the ones intended (PFMT_6 $[\beta=.68, t=26.56, p<.0 I]$ ) are significant techniques in the management of school funds by principals.

Furthermore, it was also depicted that hindering schools by host communities $\left(S C R \_I[\beta=.54, t=25.14, p<.01]\right)$, a strong synergy between principals and the leaders of the host communities (SCR_2 [ $\beta=.62, t=20.99, \mathrm{p}<.0 \mathrm{I}]$ ), the utilisation of school properties by host communities' members (SCR_3 $[\beta=.77, t=23.86, p<.01]$ ), host communities offering various forms of support to the school such as donation of land, buildings, finances and material resources etc. (SCR_4 $[\beta=.76, t=23.62, P<.0 I])$, damaging/stealing properties belonging to the school by members of host communities (SCR_5 $[\beta=.72, t=22.94, p<.0 I])$ and maintaining a strong collaboration/partnership between the school and the host community in the planning/execution of viable programmes/projects in the school (SCR_6 $[\beta=.78, t=23.87, p<.0 I])$ are significant aspects of school-community relationship. However, it is yet to be known the extent to which these various practices are adopted by the principals. Thus, an attempt to answer the research questions, as well as test the null hypotheses earlier formulated would foster better insights.

\subsection{Principals' Communication Patterns}

In order to examine the extent of principals' communication patterns in secondary schools," , the mean rating and standard deviation of the perception of respondents regarding the communication patterns adopted by the principals of their school. The results in Table 2 revealed that on the average, the extent of principals' communication patterns in secondary schools is rated with a mean of 2.49 which is below the expected average extent of 2.50 expected. This implies that the extent to which principals adopted good communication patterns was significantly low.

Table 2.

Mean rating and standard deviation of principals' communication patterns in secondary schools

\begin{tabular}{lcccccc}
\hline Items & Sum & Mean & SD & Variance & Skewness & Kurtosis \\
\hline PCP_I & 5314 & 2.52 & 1.12 & 1.26 & -0.03 & -1.36 \\
PCP_2 & 5234 & 2.48 & 1.12 & 1.25 & 0.02 & -1.36 \\
PCP_3 & 5226 & 2.48 & 1.11 & 1.23 & 0.04 & -1.33 \\
PCP_4 & 5247 & 2.49 & 1.12 & 1.25 & 0.02 & -1.36 \\
PCP_6 & 5247 & 2.49 & 1.11 & 1.23 & 0.01 & -1.34 \\
\hline Average & 5253.6 & 2.492 & 1.12 & 1.24 & 0.01 & -1.35 \\
\hline
\end{tabular}

Criterion mean $=2.5$ 


\subsection{Funds Managed by School Principals}

To answer what extent the funds are managed by school principals in secondary schools, a similar way was followed. The results contained in Table 3 reveals that the average value of 2.49 recorded for principals' funds management is approximately but not equal to the expected criterion mark of 2.50 . This implies that there was an average adoption of funds management techniques by secondary school principals.

Table 3.

Mean rating and standard deviation showing the extent of principals' funds' management in secondary schools

\begin{tabular}{lcccccc}
\hline Items & Sum & Mean & SD & Variance & Skewness & Kurtosis \\
\hline PFMT_I & 5303 & 2.52 & 1.11 & 1.24 & -0.02 & -1.35 \\
PFMT_3 & 5289 & 2.51 & 1.12 & 1.25 & -0.02 & -1.36 \\
PFMT_4 & 5178 & 2.46 & 1.12 & 1.25 & 0.05 & -1.36 \\
PFMT_5 & 5229 & 2.48 & 1.12 & 1.25 & 0.02 & -1.36 \\
PFMT_6 & 5298 & $2.5 \mathrm{I}$ & 1.11 & 1.24 & -0.02 & -1.35 \\
\hline Average & 5259.4 & 2.496 & 1.12 & 1.25 & 0.00 & -1.35 \\
\hline
\end{tabular}

Criterion mean $=2.50$

\subsection{Hypothesis}

The alternative hypothesis states that there is a significant partial and composite effects of principals' communication patterns and funds management on the school-community relationship; while the null hypothesis states that there is no significant partial and composite effects of principals' communication patterns and funds management on the school-community relationship. The partial effects depicted in Fig.2 shows that there is an inverse relationship that is statistically insignificant between principals' communication patterns and funds management techniques $(r=-.0 \mathrm{I}, \mathrm{t}=-.54, \mathrm{p}=.59)$. It was also discovered that there is a non-significant inverse relationship between principals' funds management techniques and school-community relationship $(r=$ $-.0 \mathrm{l}, \mathrm{t}=-.28, \mathrm{p}=.78)$. There is a weak positive and non-significant relationship between principals' communication patterns and school-community relationship $(r=.00, t=.08, p=.94)$. For the composite effects of principals' communication patterns and funds management on school-community relationship, the results of multiple regression analysis revealed that both predictors have no significant joint effect on the response variable $F(2,2105)=0.19, p=.83>.05$. Based on these results, the alternate hypothesis was discarded while the null hypothesis is retained.

\section{Discussion and Conclusion}

This study revealed that there is a low extent of principals' communication patterns. Although the study also revealed some very strong communication practices that could be adopted by secondary school principals to improve their patterns of communication for sound administrative effectiveness. These include maintaining close communication links with community leaders, using the mother tongue of the host community sometimes to communicate with community leaders, creating opportunities to meet with leaders of the host community to discuss vital issues affecting the school, implementing suggestions made by community leaders towards school improvement and adopting a variety of communication styles in school administration.

It is not surprising that these practices are very significant in explaining the communication patterns of school leaders since such communication practices aim at building unity, fostering cooperation and sharing the responsibility of school management between parents/community leaders and school heads. This aligns with the Humans Relations Theory which assumes that people desire to be part of a supportive team that facilitates development and growth (Mayo, 1933). This implies that the communication effectiveness of principals can be used to foster growth and development since communication can be used to build an effective workforce (Ezenwekwe 2013; Guo et al., 2015). Another explanation is anchored on the idea that free progression of information improves successful administration; communication channels encourage connections among peers in secondary schools (Anya \& Ekezie, 2019).

This study also discovered that the extent of principals' funds' management techniques is average. However, practices such as using funds to execute intended projects in the school, setting up an audit committee for the presentation of financial reports, accounting for funds generated, working harmoniously with other critical 
stakeholders in the generation, management and expenditure of school financial resources and diverting school funds into more pressing areas than the ones intended were revealed to be significant techniques principals must adopt in the management of school funds. This finding agrees with the position of Swartz (2009) that principals are freely accountable when using public assets such as school funds that are sometimes provided through citizens' taxes. It has also been previously recommended by a study that for effective management of school funds, accounting officials need to keep up a system of budgetary controls, internal audits, including appropriate procurement techniques, maintaining accountability and controlling income (Myende et al., 20I8).

This is because proper financial management plays a crucial role in eliminating conflict between stakeholders, as many are concerned about the way school financial and material resources are expended. Unaccounted funds or funds used negligently could give birth to suspicion, doubts and controversy. For instance, past investigations mirror principals' absence of eagerness to share their capacity, particularly with the school governing board to steal school reserves, creating a harmful culture of corruption (Heystek, 2004; Mestry, 2006, 2010; Xaba, 201I). These contaminated connections between the head, school governing board, educators and parents on school financial issues produced challenged bellicosity inside the school setting and its community. Therefore, in line with the Human relation theory, principals must be transparent to avoid conflicts and maintain strong ties with all relevant stakeholders.

The third finding of this study revealed that host communities serving as a hindrance to schools, maintaining a strong synergy between principals and the leaders of the host communities, the utilisation of school properties by host communities' members, host communities offering various forms of support to the school such as donation of land, buildings, finances and material resources etc., damaging/stealing properties belonging to the school by members of host communities and maintaining a strong collaboration/partnership between the school and the host community in the planning/execution of viable programmes/projects in the school are significant aspects of school-community relationship. Some of these aspects of school-community relationship are likely to affect the ties between schools and their host communities either negatively or positively.

Whatever the direction of the effect (positive or negative), the results imply that every aspect of schoolcommunity association listed above has the potential to exert significantly. Therefore, for a positive relationship, school and community leaders must maintain those aspects that are positive and avoid negative practices. This finding is grounded in the Human Relations Theory which predicted that affirmative motivation derived from team goals and greater production resulted from encouragement and positive re-enforcement from employers (Mayo, 1933). This implies that maintaining a healthy school-community relationship fosters teamwork which leads to greater production capacity due to the encouragement and re-enforcement from all parties concerned.

The fourth aspect of this study disclosed that principals' communication patterns and funds management do not significantly predict school-community relationship partially and in composite terms. The finding specifically uncovered an inverse relationship between principals' communication and funds management, and between funds management and school-community relationship. An explanation provided for the negative correlation between principals' communication patterns and funds management is the independence and parallelistic nature of the two constructs. Communication and financial management are completely separate variables that do not require the presence of the other to thrive. In other words, a person's ability to communicate effectively or otherwise may have nothing to do with his inability to manage funds or otherwise. The negative correlation between principals' management of funds and school-community relationship suggests that other things being equal, effective management of school funds would lead to a breakdown in school-community relationship and vice versa.

While this finding is quite controversial (as one would have expected the opposite), the finding may be attributed to the differences in the views of school and community leaders on how school financial resources may be expended. Furthermore, corruption may be another reason that can create such a relationship. For instance, if the school leader is corrupt in handling school funds, but include relevant stakeholders in the act (such as the case recorded in the studies of Heystek, 2004; Mestry, 2006, 20I0; Xaba, 20II), then the relationship between such parties is strengthened. That is, people are likely to participate fully in the activities of the school towards effectiveness if there is a strong relationship connecting them to institutional leaders (Owan, 2019); it must also be noted that good relationships are also built on negative things such as stealing, smoking, cultism, lesbianism etc. 
Lastly, a positive but non-significant relationship was recorded for principals' communication patterns and school-community relationship. Implying that principals' communication patterns may lead to an insignificant rate of school-community relationship. Although, the study of Owan (2019) found that school-community communication and collaboration significantly correlated with secondary school system effectiveness, it does not imply the same thing as the finding of this study. School-community communication improves the effectiveness of the school (Owan, 2019), but does not build significantly, a synergy between the school and community stakeholders. This finding may be attributed to the type, nature and quality of communication patterns adopted by the principals.

For Instance, internal communication patterns within the school would not build external links with host communities. Even where external communication links are established with host communities, the manner of the flow, the quality of the contents communicated, as well as the attitudes of the receivers including their decoding skills, are other crucial factors that can impede on its reception and understanding. Furthermore, the finding may also be attributed to the low extent to which principals adopted standard communication patterns (discovered in this study).

\section{I. Limitations and Future Implications of the Study}

This study faces a few limitations resulting from the sample derived from one state in Nigeria. The uneven representation of school and community samples may have skewed the direction of the results. Therefore, as a call, further researches are needed in the areas covered in this study for validation purposes. Secondary school principals should also ensure that they adopt good communication patterns and funds management strategies such as those explored in this study. The communication patterns and funds management strategies assessed in this study are not exhaustive, therefore, school and community leaders should also explore other effective means of communication to boost the chances of improving school-community collaboration and partnership. Funds derived from external and internal sources of the school should be used judiciously for intended purposes. Financial accountability should be the watchword of school leaders through the timely and consistent auditing process.

\section{References}

Akinwale, A. S., \& Okotoni, C. A (2018). Assessment of principal communication styles and administrative impact on secondary schools in Osun State, Nigeria. International Journal of Advanced Research and Publications, 2(I), 99-II2.

Anthony, M., Yaro, A., \& Pev, I. (2017). Influence of school-community relationship on the management of secondary schools in southern senatorial district of Taraba State, Nigeria. International Journal of Education, Humanities and Multidisciplinary Research, 9(2), I00-II4.

Anya, E. C., \& Ekezie, A. I. A. (2019). Communication: A tool for effective secondary education management in Nigeria. International Journal of Education and Evaluation, 5(6), 6I-75.

Arop, F. O., Owan, V. J., \& Ekpang, M. A. (2018a). Administrators' conflict management strategies utilization and job effectiveness of secondary school teachers in Obubra Local Government Area, Cross River State, Nigeria. IIARD International Journal of Economics and Business Management, 4(7), II-2I.

Arop, F. O., Owan, V. J., \& Ekpang, M. A. (20I8b). Effective communication management and the performance of tertiary institutions in Cross River State, Nigeria. International Journal of Current Research, 10(7), 7201972023.

Ataine, A. J., \& Nkedishu, V. C. (2017). Relevance of school-community relations in the development of primary education in Delta State, Nigeria. Journal of Research in Education and Society, 8(2), 18-27.

Atambila, A. V. (2012). Improving school-community relations in the Tolonikumbungu District of the Northern Region, Ghana. (Unpublished MA Thesis). University for Development Studies, Tamale, Ghana.

Bakwai, B. (20I3). Assessment of the role of school community relationship in the development of secondary education in Zamfara state. Sokoto Educational Review Journal (SERJ), I4(I), 35-43.

Bassey, B. A., Owan, V. J., \& Eze, E. A. (2019). Nexus between students', teachers' and school system effectiveness: Construction and factorial validity of a measuring instrument. British Journal of Education, 7(7), 62-75. 
Bavuso, P. (2016). Using technology for effective communication among schools, parents, and the community. ProQuest LLC.

Boma, P. B. (2018). Financial Management and Practices for Principals on Quality Service Delivery in Secondary Schools in Rivers State. International Journal of Innovative Finance and Economics Research, 6(2), 62-69.

Boudreaux, M. K. (2017). An analysis of urban school leaders' role in community support and involvement. School Leadership Review, I2(I), 17-28.

Brady, L. (2013). The challenge of school community relationships. Learning and Teaching, 6(2), 5-17. https://doi.org// 0.7459/lt/6.2.02

Cook, A. L., Shah, A., Brodsky, L., \& Morizio, L. J. (2017). Strengthening school-family-community engagement through community dialogues. Journal for Social Action in Counselling \& Psychology, 9(I), 9-37. https://doi.org//0.33043/JSACP.9.I.9-37

Dumitriua, C. (2013). School Violence around the World: A social phenomenon. Procedia - Social and Behavioral Sciences, 92, 299 - 308. https://doi.org/I0.1016/j.sbspro.2013.08.676

Duslak, M., \& Geier, B. (2016). Communication factors as predictors of relationship quality: A national study of principals and school counselors. Professional School Counseling, 20(I), 1096-2409.

Eubanks, K. (2017). The Relationship of school-community partnerships with ACT benchmark scores in rural Tennessee schools. (Unpublished doctoral dissertation). East Tennessee State University.

Ezenwekwe, M. C. (20I3). Teacher-principal communication patterns as correlates of effective school administration in public secondary schools in Onitsha education zone of Anambra State. (Unpublished MA Thesis). University of Nigeria, Nsukka.

Ezimoha, M., \& Ngerem, E. I. (2016). School-community relation for effective management of secondary schools in Abia State, Nigeria. LEP International Journal of Education and Practices, 2, I-9.

Federal Republic of Nigeria, FRN (2004). National policy on education (4th ed.). NERDC Publishers

Federal Republic of Nigeria, FRN (2008). National policy on education (5th ed.). NERDC Publishers

Guo, W. C., Li, T. T., \& Wu, N. (20I5). Empirical study on the effects of leader's verbal communication style on employee's job satisfaction. Journal of Human Resource and Sustainability Studies, 3, 21I-227. https://doi.org//0.4236/jhrss.2015.34027

Heystek, J. (2004). School governing bodies: The principal's burden or the light of his/her life? South African Journal of Education, 24(4), 308-3I2.

Hooge, E., Burns, T., \& Wilkoszewski, H. (2012). Looking beyond the numbers: Stakeholders and multiple school accountability. OECD Education Working Papers, No. 85. OECD Publishing.

Idris, O. S. (2018). The role of principal in school financial management: The current status. A case study in four public secondary schools in Zoba Debub, Eritrea. Journal of Education and Practice, 9(33), 53-60.

Kalemba, B. (2013). Community Participation in Education Delivery: A Study of How Community Schools Target OVCs in Chipulukusu, Zambia. (Unpublished MA Thesis). Norwegian University of Science and Technology, Trondheim, Norway.

Madukwe, E. C., Owan, V. J., \& Nwannunu, B. I. (2019). Administrative networking strategies and principals' supervisory effectiveness in secondary schools in Cross River State, Nigeria. British Journal of Education, 7(4), $39-48$.

Mayo, E. (1933). The human problems of an industrial civilisation. Cambridge, MA: Harvard.

Mbokazi, S. (2012). School-community relations as a case for school governance and support in Rural KwaZulu-Natal. In V. Chokoko \& K. M. Jorgensen (Eds), Education leadership, management and governance in South Africa. Nova Publishers.

Mbon, U. F., Ukpabio, G. E., Ekanem, E. E., Okon, J. E., Uko, E. S., Ngaji, M. N., \& Okon, E. E. (2020). Wastage of school material resources and secondary school system effectiveness: Evidence from a survey in Nigeria. Humanities and Social Sciences Letters, 8(3), 264-279. https://doi.org/I 0.18488/journal.73.2020.83.264.279

Mestry, R. (2006). The functions of school governing bodies in managing school finances. South Africa Journal of Education, 26(I), 27-38. http://www.sajournalofeducation.co.za/index.php/saje/article/view/67/63

Mestry, R. (2010). The position of principals in school financial management: A South African perspective. Journal of Educational Studies, 9(2), 36-50.

Myende, P. E., Samuel, M. A., \& Pillay, A. (2018). Novice rural principals' successful leadership practices in financial management: Multiple accountabilities. South African Journal of Education, 38(2), I-II. https://doi.org//0.I5700/saje.v38n2al447 
Nwafukwa, P. O., \& Sunday, A. N. (2015). Financial management skills required of principals for the implementation of the universal basic education programme in junior secondary schools in Ebonyi State of Nigeria. International Journal of Education, Learning and Development, 3(5), 3I-37. https://bit.ly/3mxYVim

Odigwe, F. N., Offem, O. O., \& Owan, V. J. (2018). Vocational training duration and university graduates' job performance in Cross River State, Nigeria. International Journal of Current Research, 10(7), 72024-72028.

Ogundele, M. O., Oparinde, F. O., \& Oyewale, M. K. (2012). Community-School Relations and principals' administrative effectiveness of secondary schools in Kwara State. Journal of Educational and Social Research, 2(3), 27I-275. https:// 0.590I/jesr.20I2.v2n3p27I

Okeke, I. E., Oghenetega, L. U., \& Ugulu, L. (20I4). Public relation skills of university librarians in south-east geo-political zone of Nigeria. New Media and Mass Communication, 30, 8-I2.

Okeze, W. O., Okpe, P. U., \& Ngwakwe, E. J. (2018). Assessment of financial management practices of secondary schools in Abia State. Journal of Economics and Environmental Education, 3(I), 33-46.

Omorobi, G. O., Mbon, U. F., Owan, V. J., \& Ekpenyong, J. A. (2020). Participative management practices and institutional goal attainment in Nigerian universities. American Journal of Social Sciences and Humanities, 5(I), 169-177. https://doi.org/10.20448/801.51.169.177

Owan, V. J. (2018). Conflict management strategies and secondary school teachers' job effectiveness in Obubra Local Government Area of Cross River State, Nigeria. B.Ed. Project (University of Calabar, Nigeria). https://doi.org/I0.13 I40/RG.2.2.350I5.55200

Owan, V. J. (2019). School-community relationship and school system effectiveness in secondary schools in Cross River State. World Journal of Vocational Education and Training, I(I), II-19. https://doi.org/I0.18488/journal.119.2019.11.11.19

Owan, V. J., \& Agunwa, J. N. (20/9). Principals' administrative competence and teachers' work performance in secondary schools in Calabar Education Zone of Cross River State, Nigeria. Humanities and Social Sciences Letters, 7(I), 20-28. https://doi.org/10.18488/journal.73.2019.7I.20.28

Owan, V. J., Arop, F. O., \& Agunwa, J. N. (2019). Path analysis of innovative management practices and secondary school system effectiveness in Cross River State, Nigeria. British Journal of Education, 7(3), 58-68.

Owan, V. J., Nwannunu, B. I., \& Madukwe, E. C. (2018). Problems of school management and students' academic performance in secondary schools in Calabar education zone, Cross River State, Nigeria. International Journal of Research and Innovation in Social Science (IJRISS), 2(10), I20-127.

Palmieri, C., \& Palma, M. (2017). The relationship between school and community as an opportunity to rethink teaching. US-China Education Review, 7(I), 49-57. https://doi.org/I0.17265/2I6I-623X/20I7.01.004

Peretomode, V. F. (20I2). Theories of management: Implications for educational administration. Abraka, Nigeria: University Printing Press

Russell, K. A. (2009). Community participation in schools in developing countries: Characteristics, methods and outcomes. Retrieved from https://eric.ed.gov/?id=ED5192/4

Swartz, L. (2009). Financial management in schools. PhD Thesis (Rice University, Houston, TX).

Udoh-Uwah, O. E., Ubok-Obong, I., \& Etim, M. E. (20I8). Financial management competence of principals and attainment of secondary school goals in Calabar Education Zone of Cross River State, Nigeria. Journal of Education and Practice, 9(4), 36-39.

Ukpong, N. N., \& Uzoigwe, M. C. (2019). Management of Internally Generated Revenue (IGR) and sustainability of University Education in Cross River State, Nigeria. Journal of Education and Practice, 10(5), II6-I25.

Ungar, M. (2009). Overprotective parenting: Helping parents provide children the right amount of risk and responsibility. American Journal of Family Therapy, 37(3), 258-27I. https://doi.org/10.1080/01926/80802534247

Waek, B. I. (2017). Impact of parental and community involvement in schools on teacher attendance in junior high schools in the Northern Region of Ghana: Case study of East Mamprusi District. (Unpublished MA Thesis). University for Development Studies, Tamale, Ghana.

Xaba, M. I. (20II). The possible cause of school governance challenges in South Africa. South African Journal of Education, 3 I (2), 20I-2II. https://doi.org/I0.I5700/saje.v3 In2a479. 


\section{APPENDIX}

\section{PRINCIPALS' COMMUNICATION, FUNDS MANAGEMENT AND SCHOOL-COMMUNITY RELATIONSHIP QUESTIONAIRE (PCFMSCRQ)}

\section{Dear Respondent,}

The essence of this questionnaire is to obtain data with respect to the above-mentioned caption. Your assistance in completing the questionnaire accurately and completely in adherence to the instructions provided will contribute positively to the accomplishment of this study's objectives. All information will be treated confidentially. Thanks for your cooperation.

\section{SECTION A}

INSTRUCTION: Please fill in the blank space and $[\sqrt{ }]$ as appropriate.

Sex: Male [ ] Female [ ]

Occupation: Civil service [ ]; Farming [ ]; Military [ ]; Business [ ]; Others (specify)

Years of work experience: Less than 5 years [ ]; 5 - 10 years [ ]; $11-16$ years [ ]; 17 years+ [ ]. Educational Qualification: OND/NCE [ ]; HND/First Degree [ ]; PGDE/Masters [ ]; PhD [ ].

\section{SECTION B}

Please respond by ticking in the column which best represent your choice of answers

SA - Strongly Agree
A - Agree
$D$ - Disagree
SD - Strongly disagree

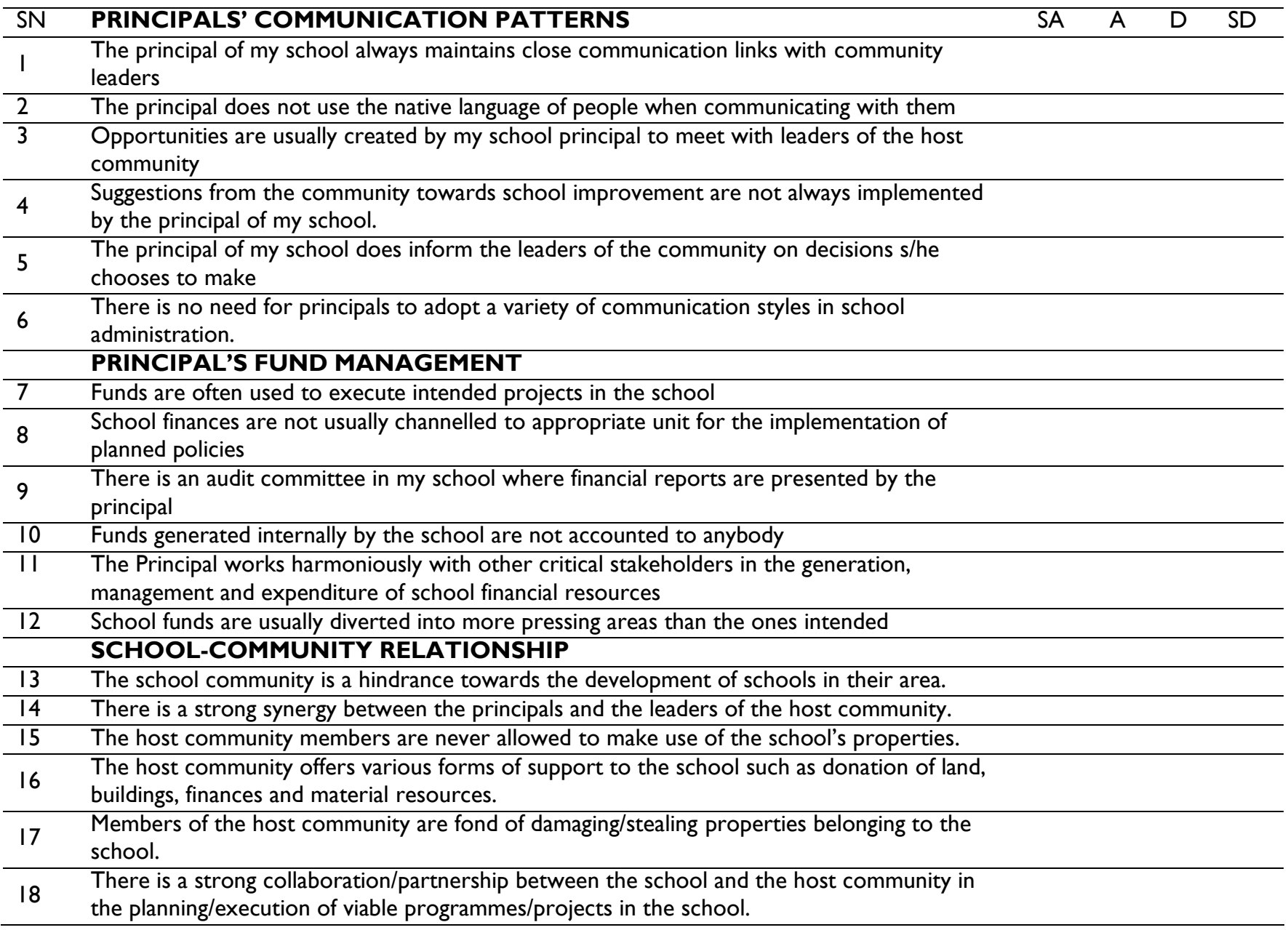

